\title{
Decision Making Styles among Professor in Central University of Bihar - an Empirical Study of Predictors
}

\author{
Sushil Kumar, Neeraj Gautam \\ Department of Humanities and Social Sciences, Motilal Nehru National Institute of Technology, Allahabad, India
}

Email address:

Kumarsushi67@gmail.com (S. Kumar), alldetailorm@gmail.com (N. Gautam)

\section{To cite this article:}

Sushil Kumar, Neeraj Gautam. Decision Making Styles among Professor in Central University of Bihar - an Empirical Study of Predictors. International Journal of Law and Society. Vol. 1, No. 2, 2018, pp. 84-91. doi: 10.11648/j.ijls.20180102.15

Received: October 28, 2017; Accepted: December 13, 2017; Published: March 8, 2018

\begin{abstract}
Decision making is one of the most important elements in the functioning of an organisation. Every day we face numerous alternatives and have to make a decision about which one to select. A well-crafted decision can help the organisation move in the right direction and affect people across the organisation to a large extent, thus to be effective, one needs to be aware of their decision making styles so that an attempt can be made to evolve and work on inefficient and ineffective styles to make themselves better equipped to make the decisions that are required. From an organisational point of view, since the success or failure can be vastly impacted by decisions made by the employees it is important that they find out the decision making style and then use it for further developmental purposes or even for finding the right person-job fit. Since a university is an organisation and professors form a core group whose decisions impact not only the success of the institution but also the future of our country as a consequence of the bearing their decisions have on the students who are the future leaders of this nation. In the Indian context, with the youth constituting a major part of the population, the impact of professors is extremely high. Research suggests that while people may have different decision making styles but they have a high predisposition towards one particular style and that is explored in this study. The study delved into the impact of personality types on decision making styles and it revealed that there is a direct and positive relationship between conscientiousness and a rational decision making style, between neuroticism and an avoidant decision making style, openness to experience and an intuitive decision making style. A demographic factor, age and its impact on intuitive decision making style was tested which indicated that no such relationship exists. Finally, the impact of self-esteem on an individual's decision making style suggests that people with high self-esteem have a predisposition towards a rational decision making style and they are unlikely to have an avoidant decision making style.
\end{abstract}

Keywords: Decision Making Style, Intuitive, Predisposition \& Right Person-Job Fit

\section{Introduction}

\subsection{Decision Making}

Every day we are presented with various situations where there is a constant need to make decisions. These decisions that we make play a significant role in shaping our lives. Made consciously or unconsciously decisions are tools that we use in everyday life as we face opportunities, threats and uncertainties. Our success in the various roles we play depends on these decisions (Hammond and Raiffa 1999).

Professionals in any workplace need to plan, organise, implement different strategies in ways they believe will meet the organisation goals in the best possible way. These are complex tasks because most of them are interrelated and one decision can have far reaching implications on various aspects of the organisational strategy. Thus decisions that are taken at the workplace by the employees have a significant impact on the organisational success (Forgionne 1991). Decision making is one of the key functions for any professional and it is this factor on which the success or failure of an organisation depends to a great extent. Research has shown that decision making is the most fundamental activity in an organisation and the quality of decisions made influence the effectiveness of the decision maker as a key member of the organisation and also impacts the organisational success (Leonard, Scholl, and Kowalski 1999). 


\subsection{Decision Making and Decision Makers}

Cyert and March (1963) envisioned organisations as decision making fields with powerful influences of factors like uncertainty, conflict of interest and political behaviour. Study conducted by (Mintzberg, Raisinghani and Theoret 1976) and others has resulted in interest in understanding organisations from decision making perspective. Decision making is central to organisations performance and therefore researchers have found many approaches to study this concept (Butler 1992). In an educational institution, the responsibility of the decision makers is not just to make a decision but take into account the ethical dilemmas. Ethics in an educational institution stem

\subsection{Statement of the Problem}

Decision-making is a central element in any organization. Universities are organisations and are run by administrators and teachers. A well-known and good university is one which is run efficiently and where the teaching is known to be world class. Thus teachers and professors are the key resources in the success of an educational institution. As with managers in an organisation, teachers and professors are the key resources and make decisions in universities and that have an impact on the success of those institutions. The decision making is influenced by a variety of factors like talent, skills, experience etc. The decision style of the teachers is also a factor that affects success of those decisions but it is a hidden factor and therefore an exploration of the decision styles used by teachers and the factors that impact those decision styles is essential.

\subsection{Purpose of the Study}

The purpose of this study is to explore the decision making styles of the professors in a Central University in Bihari teaching the undergraduate program. Teaching is a process of making and executing decisions, before, during and after instruction to facilitate and increase the prospect of learning by the students. The decisions and actions of the instructor in an educational institution must reflect the awareness of the environment e.g. state and ability of the learner; this will increase the probability of learning.

\section{Review Literature}

\subsection{Understanding Decision Making}

Decision making theories are used as tools to assist decision-makers in making choices among the numerous alternatives. The original decision theories like, expected value theory and subjective expected utility theory were based on assumptions of rationality to gauge decision making behaviour in quantitative terms (Edwards and Fasolo 2001). However the concept of bounded rationality is a severe limitation to the normative decision making theories.

Bounded Rationality as proposed by Herbert Simon states that in the process of decision-making, the rationality of individuals is restricted by information available to them, limited time and cognitive limitations of their minds.

Expected value theory states that a person should choose the option with the highest expected value.

Subjective expected utility theory is a method in decision theory in the presence of risk promoted by Savage in 1954 which states that if axioms of rationality are observed by an individual then, if you believe an uncertain event has possible outcomes $\left\{x_{-} i\right\}$ with a utility of $u\left(x \_i\right)$, then your choices can be explained as arising from a function in which you believe that there is a subjective probability of each outcome is $\mathrm{P}\left(\mathrm{x} \_\mathrm{i}\right)$, and your subjective expected utility is the expected value of the utility.

\subsection{Decision Making Styles}

Decision-making style is the learned or habitual response or predisposition with which people make decisions (Scott and Bruce 1995) and these decision making tendencies depend on individual differences among people. There is a lack of consensus about the theoretical basis of decision making styles. While some researchers maintain that decision-making styles characterize stable individual differences across time and situations, others believe that it is a state like quality i.e. it is a fluid and ever changing state and people keep alternating among the different styles. Kahneman (1981) discusses two kinds of styles i.e. intuition and reasoning where intuition is a style characterized by adjectives like quick, automatic, associative, and emotionally driven while the latter associated with diametrically opposite adjectives like slow, controlled, and effortful. While another point of view is that these two styles are related to individual differences and make a distinction among people depending on the way they process information and make decisions over time (Epstein, et al. 1996).

\subsection{Measuring Decision Making Style}

There are numerous classifications of decision making styles by different researchers. Decision making is about understanding a situation with the help of the information available, processing the information and listing the alternatives and finally choosing one option. The focus area for classification of decision making styles has been different for different researchers; some focus on qualitative differences in how individuals go through a process of sense making and processing of the information they gather (Harren, A Model of Career Decision Making for College Students 1979), while certain others focus on the amount of information collected and the number of alternatives considered in the process of decision making (M. J. Driver, Individual decision making and creativity 1979).

a. Directive Style. This style has a low tolerance for ambiguity and there is preference for structure and specific information. There is little information and few alternatives so the speed of decision making is fast. It is associated with a high need for power and is often 
autocratic.

b. Analytical style. This style has a greater tolerance for ambiguity than directive style and has a desire for more information and looks at many alternatives. This style is associated with a greater ability to deal cope with new situations.

c. Conceptual Style. This style is associated with a high level of cognitive complexity and people orientation. Data from various sources is used to make decisions. Further, it is related to a creative bent of mind who can easily understand complex relationships.

\subsection{Cognition}

The dictionary meaning of the word cognition is A mental act of attaining information through processes including awareness, perception, reasoning, judgement etc.

Information processing style which is often termed as cognitive style is increasingly seen as one of the basis for understanding decision making behaviour, conflict, group processes etc. (Leonard and Scholl 1999). According to Kozhevnikov (2007) cognitive styles of individuals are related to general approaches of functioning of an individual's mental faculties and therefore processing of information irrespective certain special incidental cases and drawing at conclusions based on observations.

\subsection{Risk Taking}

In classical decision theory risk is a factor that reflects variation in the distribution, likelihood and subjective values of the possible outcomes. The element of risk is embedded in the idea of making a choice which will be impacted by the expected return of an alternative. Most theories of choice assume that the choice which offers a larger expected return is preferred over the one that delivers smaller returns, all other factors (e.g. risk) remaining constant. It is generally believed that people prefer lower risk to higher risk and thus expected value is presumed to be positively related and risk negatively related to the attractiveness of an alternative (Ross 1981).

\subsection{Personality}

Trait Theory. Traits symbolize "individual characteristics, inherited or acquired", and refer to "tendencies to act or react in certain ways" (Drever 1964). This theory posits that a person's behaviour is influenced by the traits they possess; as a consequence of these traits individuals are more predisposed to acting in a certain way thereby aligning with their own traits in a given situation. Traits are seen to lend a certain consistency to behaviour and in a sense form broad guides for understanding an individual as they are expected to be stable (Kidder 2005 as cited in Carpenter, 2006).

The dimensions of all the personality types, as listed in the IPIP NEO-PI measures, are listed below: (Seibert and Zhao 2006)
Table 1. Traits of Personality Types.

\begin{tabular}{lll}
\hline Broad Domain & & Sub Traits \\
\hline \multirow{2}{*}{ Neuroticism } & Anxiety & Self-Consciousness \\
& Anger & Immoderation \\
& Depression & Vulnerability \\
& Self-Efficacy & Achievement-Striving \\
Conscientiousness & Orderliness & Self-Discipline \\
& Dutifulness & Cautiousness \\
& Imagination & Adventurousness \\
Openness & Artistic Interests & Intellect \\
& Emotionality & Liberalism \\
& Friendliness & Activity Level \\
Extraversion & Gregariousness & Excitement-Seeking \\
& Assertiveness & Cheerfulness \\
& Trust & Cooperation \\
Agreeableness & Morality & Modesty \\
& Altruism & Sympathy \\
\hline
\end{tabular}

Intuitive decision making has been defined by Judge and Robbins (2006) as "a subconscious process created out of a person's experiences". Thus we can say that the conceptual framework for intuition includes experience, insight and a gut feeling. With age, the experience increases and this may impact the predisposition towards intuitive decision making.

Thus taking all the above stated findings into account, we propose a relation between constructs of personality and decision making styles

$\mathrm{H1}$ : Conscientiousness is positively related to a rational decision making style

$\mathrm{H} 2$ : Neuroticism is positively related to an avoidant decision making style

$\mathrm{H} 3$ : Openness to experience is positively related to an intuitive decision making style

$\mathrm{H} 4$ : Age is positively related to intuitive decision making style

\subsection{Conceptual Framework}

In light of the hypothesis derived and an overall picture based on the existing literature, the following model is proposed for the research

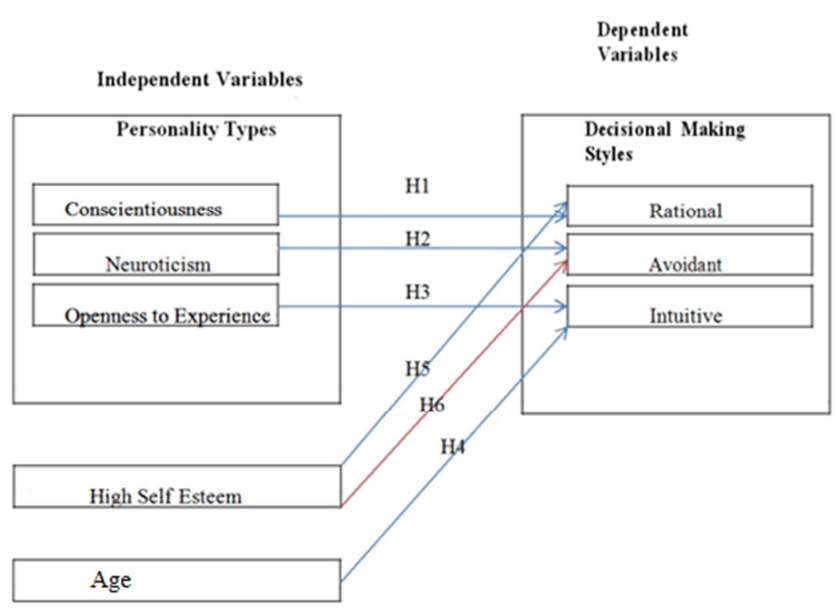

Figure 1. Conceptual Framework Proposed. 


\section{Research Methodology}

\subsection{Research Design}

The aim of the research was to test the factors that have an impact on decision making styles of teachers. For this an adequate sample size was needed with teachers having a minimum of 1 year teaching experience. The survey was distributed to 164 professors. They were apprised of the aim of the research by the researcher. Envelops with the questionnaire were distributed to the teachers using convenience sampling. There was no name required to be filled in the form to enable the confidentiality and anonymity of the questionnaire and evoke honest and unbiased responses from the participants. In this study, quantitative research methods was used for testing the hypotheses and the model developed based on the literature.

\subsection{Sampling}

For this study Convenience sampling was used. The basic criterion was at least 1 year of teaching experience at the university level. This form of sampling allows researchers to use subjects for the study even without formal access to lists of the population. In this study also, to get a formal list of all teachers across a Central University would be almost impossible and thereby this method of sampling was adopted.

\subsection{Profile of the Participants}

a) The teachers covered were teaching undergraduate students a variety of subjects ranging from Political Science, History, Sociology, Mathematics, Economics and Commerce.

b) There were 150 respondents among which 125 were women and 25 were men

c) The mean age of the respondents is 38.5 years with a standard deviation of 9.46 .

d) The mean years of experience of all the professors is 12.6 years with a standard deviation of 9.5 .

\subsection{Tools for Data Collection}

To ensure the validity of this study, standard tools which have been used extensively by researchers for various studies to measure the variables being considered in this study. These instruments were tested again for its reliability with respect to the chosen sample for this study. The results were positive and all the scales were valid for the sample.

\subsection{Dependent Variable}

Decision Making. Decision-making style was measured using the Scott and Bruce's (1995) General Decision-Making Style Inventory. The reliability and validity was tested by Scott and Bruce with four study samples consisting of 1943 respondents. Internal-consistency and factor-stability analyses were also conducted for the scale. This instrument has been extensively used in research. The validity and reliability of this inventory has been confirmed (Spicer and Sadler-Smith 2005, Kao \& Kao 2007).

This instrument comprises of 25 items scored on a five point likert scale. It has 5 subscales to measure the different styles with 5 items for each style:

1. Avoidant (e.g. I avoid making important decisions until the pressure is on)

2. Dependent (e.g. I often need the assistance of other people when making important decisions)

3. Intuitive (e.g. When making a decision, I trust my inner feelings and reactions )

4. Rational (e.g. My decision making requires careful thought)

5. Spontaneous (e.g. I generally make snap decisions)

A high score on any of the five scales indicates a higher presence of that particular decision-making style. Cronbach's alpha was calculated for each individual subscale comprising five items, it established an acceptable reliability score with the following values: Avoidant: 0.832, Dependent: 0.822, Intuitive: 0.904, Rational: 0.887, Spontaneous: 0. 890 .

\subsection{Independent Variables}

Personality. Personality type was measured using the Big Five Inventory (John, Donahue, and Kentle 1991). This inventory comprises 44 items with subscales for each of the five personality types: Agreeableness, Conscientiousness, Extraversion, Openness to Experience, Neuroticism. The BFI comprises short phrases as questions which are based upon the trait adjectives identified to be the prototypical indicators of the Big Five (John, 1989, 1990). This is one of the most widely used instrument for personality since it is short and easily understood as well as efficient (Pervin and John 999). Literature gives proof of the external validity of this instrument. E.g. In job performance studies, the Big Five has been found to be related to important outcomes in the workplace (Barrick \& Mount 1991, Mount, Barrick, \& Stewart 1998). The responses are required on a five point likert scale. Cronbach's alpha was calculated for each individual subscale comprising five items, it established an acceptable reliability score with the following values: Agreeableness: 0.852, Conscientiousness: 0.901, Extraversion: 0.950, Openness to Experience: 0.869 , Neuroticism: 0.851.

Self-Esteem. The Rosenberg self-esteem scale (Rosenberg, 1965 ) is an index of an individual's global/ trait self-esteem and the reliability and the validity of the questionnaire has been confirmed numerous times in previous researches (e.g., Baumeister, Tice, \& Hutton, 1989; Rosenberg, 1979). This questionnaire consists of 10 items with a five-point Likert scale ranging from strongly agree to strongly disagree, of which five items were reverse-scored. For this research, Cronbach's alpha was calculated it established an acceptable reliability score of 0.928 . The total number of variables involved in the study was 11 and the number of items in the survey.

Questionnaire is 79. A concern in the study is the use of selfreports for Decision Making Style and Self-Esteem which people may not be keen to share. However care was taken to 
ensure that the identity of respondents is kept confidential.

\section{Analysis and Interpretation of Data}

The data was collected using standard scales and analysed using SPSS. A variety of tests were conducted to prove the hypothesis.

\subsection{Response Rate}

The researcher went to the universities and explained to the teachers the purpose of the research. Thus the population consisted of all teachers across the 4 colleges that were approached for data collection. However, due to various reasons some teachers declined to fill the survey stating that it required very personal information. The questionnaires were distributed to 200 teachers. Some filled and returned it at that time itself while certain others promised to return it in a few days.

Amongst the 200 questionnaires distributed only 164 responses were received after repeated follow ups with the respondents. This represented $82 \%$ response rate. Out of these 164 responses, 14 were unusable. Thus out of the final 164 responses, only 150 have been used for the final data analysis. This represents use of $91 \%$ of the questionnaires returned.

The returned surveys were received from all types of participants (teachers from different departments in no particular pattern)

\subsection{Descriptive Statistics for the Data}

Table 2 presents the descriptive statistics for all the dependent and independent variables i.e. the Personality Variable, self-esteem variable and the decision making style.

The values for decision making style vary from 1.12 to 4.64 with a mean value of 2.71 .

The highest score is for avoidant decision making style with a score higher than the mean i.e. 3.07 followed closely by spontaneous decision making style with a score of 2.77 . The mean score of the five Personality items falls in the range of $1.40-4.15$ and the overall mean score is 2.68 . The highest score is for neuroticism with a mean value of 3.06 followed by extraversion with a mean value of 2.82 . Examining self-esteem we see that the scores vary from 1.20 to 4.40 and the mean score is 2.65 which indicate that the sample is leaning towards a high self-esteem.
Table 2. Descriptive Statistics.

\begin{tabular}{lllll}
\hline Variables & Minimum & Maximum & Mean & $\begin{array}{l}\text { Std. } \\
\text { Deviation }\end{array}$ \\
\hline Personality & & & & \\
Types & 1.44 & 4.22 & 2.62 & 0.83 \\
Conscientiousness & 1.22 & 3.89 & 2.18 & 0.64 \\
Agreeableness & 1.38 & 4.50 & 2.82 & 0.97 \\
Extraversion & 1.88 & 4.25 & 3.06 & 0.75 \\
Neuroticism & 1.10 & 3.90 & 2.73 & 0.54 \\
Openness to Experience & & & & \\
Overall & 1.40 & 4.15 & 2.68 & 0.74 \\
Personality score & 1.20 & 4.40 & 2.65 & 0.90 \\
Self Esteem & & & & \\
Decision Making & & & & \\
Styles & 1.00 & 4.60 & 2.61 & 1.00 \\
Rational & 1.20 & 4.80 & 3.07 & 0.92 \\
Avoidant & 1.20 & 4.80 & 2.59 & 0.98 \\
Intuitive & 1.20 & 4.60 & 2.51 & 0.83 \\
Dependent & 1.00 & 4.40 & 2.77 & 1.02 \\
Spontaneous & & & & \\
Overall Decision & 1.12 & 4.64 & 2.71 & 0.95 \\
Making style & & & & \\
\hline
\end{tabular}

\subsection{Reliability}

Cronbach's aloha is an index of reliability linked to the variation accounted for by the real scores of the underlying construct. It is a tool which is used to measure internal consistency of the items thereby explaining the extent to which items in the questionnaire are related to one another. The reliability scores were obtained for each subscale in the questionnaire and cronbach's alpha was found to ensure adequate values prior to starting any further analysis. All the scales were found to be valid for the sample. The cronbach alpha scores found have been mentioned in Table 3

Table 3. Cronbach Alpha Reliability Values.

\begin{tabular}{ll}
\hline Scale & Cronbach's Alpha \\
\hline Avoidant Decision Making Scale & 0.832 \\
Dependent Decision Making Scale & 0.822 \\
Intuitive Decision Making Scale & 0.904 \\
Rational Decision Making Scale & 0.887 \\
Spontaneous Decision Making Scale & 0.877 \\
Extraversion Personality Scale & 0.950 \\
Agreeableness Personality Scale & 0.852 \\
Conscientiousness Personality Scale & 0.901 \\
Openness to Experience Personality Scale & 0.897 \\
Neuroticism Personality Scale & 0.851 \\
Self-Esteem Scale & 0.928 \\
\hline
\end{tabular}

Table 4. Bivariate correlation of Decision Making Style with Personality Types and Self Esteem

\begin{tabular}{|c|c|c|c|c|c|c|c|c|c|c|c|c|c|}
\hline & & Conscien & & & Neuroti & & Open & Self & Depend & Spontan & Agreeab & Extra & \\
\hline & & tiousness & Rational & Avoidant & cism & Intuitive & ness & esteem & ent & eous & leness & Version & Age \\
\hline \multirow[t]{3}{*}{$\begin{array}{l}\text { Conscienti } \\
\text { ousness }\end{array}$} & $\begin{array}{l}\text { Pearson } \\
\text { Correlation }\end{array}$ & \multirow[t]{2}{*}{1} & $.439(* *)$ & $-.262(* *)$ & $\begin{array}{l}- \\
.455(* *)\end{array}$ & .022 & .036 & $.319(* *)$ & -.069 & -.124 & -.024 & -.071 & .005 \\
\hline & Sig. (2-tailed) & & .000 & .001 & .000 & .788 & .660 & .000 & .398 & .131 & .774 & .386 & .954 \\
\hline & $\mathrm{N}$ & 150 & 150 & 150 & 149 & 150 & 150 & 150 & 150 & 150 & 150 & 150 & 150 \\
\hline \multirow[t]{3}{*}{ Rational } & $\begin{array}{l}\text { Pearson } \\
\text { Correlation }\end{array}$ & $.439(* *)$ & 1 & $-.365(* *)$ & $\begin{array}{l}- \\
.325(* *)\end{array}$ & -.092 & .056 & $.452(* *)$ & .055 & -.079 & -.003 & -.048 & -.107 \\
\hline & Sig. (2-tailed) & .000 & & .000 & .000 & .264 & .494 & .000 & .504 & .337 & .969 & .556 & .193 \\
\hline & $\mathrm{N}$ & 150 & 150 & 150 & 149 & 150 & 150 & 150 & 150 & 150 & 150 & 150 & 150 \\
\hline
\end{tabular}




\begin{tabular}{|c|c|c|c|c|c|c|c|c|c|c|c|c|c|}
\hline & & Conscien & & & Neuroti & & Open & Self & Depend & Spontan & Agreeab & Extra & \\
\hline & & tiousness & Rational & Avoidant & cism & Intuitive & ness & esteem & ent & eous & leness & Version & Age \\
\hline \multirow[t]{3}{*}{ Avoidant } & $\begin{array}{l}\text { Pearson } \\
\text { Correlation }\end{array}$ & $-.262(* *)$ & $\begin{array}{l}- \\
.365(* *)\end{array}$ & 1 & $.517(* *)$ & -.120 & -.038 & $.665(* *)$ & -.012 & .002 & .073 & $.233(* *)$ & .068 \\
\hline & Sig. (2-tailed) & .001 & .000 & & .000 & .143 & .647 & .000 & .889 & .978 & .372 & .004 & .411 \\
\hline & $\mathrm{N}$ & 150 & 150 & 150 & 149 & 150 & 150 & 150 & 150 & 150 & 150 & 150 & 150 \\
\hline \multirow[t]{3}{*}{$\begin{array}{l}\text { Neuroti } \\
\text { csm }\end{array}$} & $\begin{array}{l}\text { Pearson } \\
\text { Correlation }\end{array}$ & $-.455(* *)$ & $\begin{array}{l}- \\
.325(* *)\end{array}$ & $.517(* *)$ & 1 & -.076 & .007 & $.427(* *)$ & .108 & -.003 & .157 & $.292(* *)$ & .072 \\
\hline & Sig. (2-tailed) & .000 & .000 & .000 & & .355 & .929 & .000 & .189 & .970 & .056 & .000 & .382 \\
\hline & $\mathrm{N}$ & 149 & 149 & 149 & 149 & 149 & 149 & 149 & 149 & 149 & 149 & 149 & 149 \\
\hline \multirow[t]{3}{*}{ Intuitive } & $\begin{array}{l}\text { Pearson } \\
\text { Correlation }\end{array}$ & .022 & -.092 & -.120 & -.076 & 1 & $.510(* *)$ & .077 & .020 & $.182(*)$ & -.039 & $.274(* *)$ & -.034 \\
\hline & Sig. (2-tailed) & .788 & .264 & .143 & .355 & & .000 & .352 & .811 & .026 & .638 & .001 & .684 \\
\hline & $\mathrm{N}$ & 150 & 150 & 150 & 149 & 150 & 150 & 150 & 150 & 150 & 150 & 150 & 150 \\
\hline \multirow{2}{*}{ Openness } & Sig. (2-tailed) & .660 & .494 & .647 & .929 & .000 & & .855 & .873 & .541 & .525 & .000 & .225 \\
\hline & $\mathrm{N}$ & 150 & 150 & 150 & 149 & 150 & 150 & 150 & 150 & 150 & 150 & 150 & 150 \\
\hline \multirow[t]{3}{*}{$\begin{array}{l}\text { Self } \\
\text { Esteem }\end{array}$} & $\begin{array}{l}\text { Pearson } \\
\text { Correlation }\end{array}$ & $.319(* *)$ & $.452(* *)$ & $-.665(* *)$ & $\begin{array}{l}- \\
.427(* *)\end{array}$ & .077 & -.015 & 1 & .020 & -.057 & -.010 & -.103 & -.119 \\
\hline & Sig. (2-tailed) & .000 & .000 & .000 & .000 & .352 & .855 & & .806 & .491 & .902 & .209 & .146 \\
\hline & $\mathrm{N}$ & 150 & 150 & 150 & 149 & 150 & 150 & 150 & 150 & 150 & 150 & 150 & 150 \\
\hline \multirow[t]{3}{*}{ Dependent } & $\begin{array}{l}\text { Pearson } \\
\text { Correlation }\end{array}$ & -.069 & .055 & -.012 & .108 & .020 & .013 & .020 & 1 & -.090 & $.387(* *)$ & .045 & .008 \\
\hline & Sig. (2-tailed) & .398 & .504 & .889 & .189 & .811 & .873 & .806 & & .271 & .000 & .586 & .922 \\
\hline & $\mathrm{N}$ & 150 & 150 & 150 & 149 & 150 & 150 & 150 & 150 & 150 & 150 & 150 & 150 \\
\hline \multirow[t]{2}{*}{$\begin{array}{l}\text { Spontaneo } \\
\text { us }\end{array}$} & $\begin{array}{l}\text { Pearson } \\
\text { Correlation }\end{array}$ & -.124 & -.079 & .002 & -.003 & $.182(*)$ & .050 & -.057 & -.090 & 1 & $-.172(*)$ & $.777(* *)$ & .085 \\
\hline & Sig. (2-tailed) & .131 & .337 & .978 & .970 & .026 & .541 & .491 & .271 & & .035 & .000 & .301 \\
\hline \multirow{2}{*}{$\begin{array}{l}\text { Agreeable } \\
\text { ness }\end{array}$} & Sig. (2-tailed) & .774 & .969 & .372 & .056 & .638 & .525 & .902 & .000 & .035 & & .003 & .755 \\
\hline & $\mathrm{N}$ & 150 & 150 & 150 & 149 & 150 & 150 & 150 & 150 & 150 & 150 & 150 & 150 \\
\hline \multirow[t]{3}{*}{$\begin{array}{l}\text { Extraversi } \\
\text { on }\end{array}$} & $\begin{array}{l}\text { Pearson } \\
\text { Correlation }\end{array}$ & -.071 & -.048 & $.233(* *)$ & $.292(* *)$ & - $274(* *)$ & $.334(* *)$ & -.103 & .045 & $.777(* *)$ & $.238(* *)$ & 1 & -.064 \\
\hline & Sig. (2-tailed) & .386 & .556 & .004 & .000 & .001 & .000 & .209 & .586 & .000 & .003 & & .436 \\
\hline & $\mathrm{N}$ & 150 & 150 & 150 & 149 & 150 & 150 & 150 & 150 & 150 & 150 & 150 & 150 \\
\hline \multirow[t]{3}{*}{ Age } & $\begin{array}{l}\text { Pearson } \\
\text { Correlation }\end{array}$ & .005 & -.107 & .068 & .072 & -.034 & .100 & -.119 & .008 & .085 & .026 & -.064 & 1 \\
\hline & Sig. (2-tailed) & .954 & .193 & .411 & .382 & .684 & .225 & .146 & .922 & .301 & .755 & .436 & \\
\hline & & 150 & 150 & 150 & 149 & 150 & 150 & 150 & 150 & 150 & 150 & 150 & 150 \\
\hline
\end{tabular}

Correlation is significant at the 0.01 level (2-tailed).

Correlation is significant at the 0.05 level (2-tailed).

\section{Discussions}

The fundamental question that guided this study was, are there certain inherent factors in a person that result in different behavior and decision making in similar situations by different people. Based on literature five hypothesis examined the potential influence of two key factors on decision making i.e. personality and self-esteem. These are two factors that are seen to be unique to individuals.

The main findings of the study were

a) H1: There is a positive relationship between Conscientiousness and Rational Decision Making Style

b) H2: There is a positive relationship between
Neuroticism and Avoidant Decision Making Style

c) H3: There is a positive relationship between Openness to Experience and Intuitive Decision Making Style

d) H4: There is a positive relationship between Intuitive Decision Making Style and Age

e) H5: There is a positive relationship between High SelfEsteem and Rational Decision Making Style

f) H6: There is a negative relationship between High Self-

Esteem and an Avoidant Decision Making Style

This relationship was explored in this study. Factor analysis carried out on both the variables indicated a valid and adequate scale and sample and extracted one component for intuitive decision making with significant factor loadings while two components were extracted for openness to 
experience and both were marred by cross loadings thereby a new variable was created with the factors that had significant loadings and that was used for further analysis. Thereafter the correlation between the two factors was significant with a coefficient of $0.510^{* *}$. Further the regression between these two variables indicates a significant positive relationship with a $\mathrm{B}$ value of 0.659 , thus proving the hypothesis.

Limitations and Implications for Future Research

There are a number of limitations of this study which must be explicitly mentioned for individuals using the findings of the study as well as evaluating the result.

Firstly the focus was on Teachers in a Central University in Bihari and since there was no available list of all teachers a convenience sample was used.

Second limitation is that it did not include teachers in a private university where the administration and work environment may be different resulting in a different behaviour which may have an impact on the final outcome being explored. This can be done in future research to compare the differences of the external environment and the organisation on decision making style.

Third limitation is more women than men in the sample which is again due to lack of access to all the teachers. Further studies in this area must try to have equal samples of men and women and explore the moderating impact of gender on decision making styles, styles then they can understand their co-workers better and this will go a long way in enhancing communication among them.

\section{Conclusion}

The theme for this study was decision making which is a cognitive process of making a choice between the various alternatives available to an individual to be able to select a path that leads to the desired goal. This is an extremely important construct since life is a series of decisions that are made and thereafter follow the consequences. What we eventually become is a consequence of the decisions that we make at different stages in our life. Not only do our decisions impact our personal lives but also play a significant role in the success or failure of the organisation that we work for thereby making it is an important criterion from an organisational perspective. Thus it is one of the key factors that need to be analysed and explored at the time of hiring, training and promoting in the organisation.

\section{References}

[1] Aikins, Deane E, and Michelle G Craske. "Cognitive theories ofgeneralized anxiety disorder." The Psychiatric Clinical of North America Vol 24 No 1, 2001 57-71.

[2] Alexander, Simon H. The New Science of Management Decision. New York: Harper and Row, 1960.

[3] Anthony, Danu B, Joanne V Wood, and John G Holmes. "Testing sociometer theory: Self-esteem and the importance of acceptance for social decision-making." journal of
Experimental Social Psychology Vol 43 No 3, 2007: 425-432.

[4] Barrick, Murray R., and Michael K. Mount. "The Big Five Personality dimensions and job performance: A meta analysis." Personnel Psychology, 1991: 1-26.

[5] Baumeister, Roy F, and Mark R Leary. "The need to belong: Desire for interpersonal attachments as a fundamental human motivation.” Psychological Bulletin Vol 117, 1995: 497-529.

[6] Baumeister, Roy F, Karen Dale, and Kristin L Sommer. "Freudian Defense Mechanisms and Empirical Findings in Modern Social Psychology: Reaction Formation, Projection, Displacement, Undoing, Isolation, Sublimation, and Denial." Journal of Personality Vol 66 No 6, 1998: 1081-1124.

[7] Bednar, Richard L, and Scott R Peterson. Self-esteem: Paradoxes and Innovations in. Washington, DC: American Psychological Association, 1989.

[8] Bernstein, Basil B. Class, Codes and Control: Towards a Theory of Educational Transmission, Volume 3 as cited in Harthi, Hamood A; Ginsburg, Mark B 'Student-Faculty Power/Knowledge Relations:The implications of the internet in the College of Education, Sultan Qaboos University'. London: Routledge \& Kegan Paul, 1975.

[9] Beugelsdijk, Sjoerd, and Roger Smeets. "Entrepreneurial Culture and Economic Growth." american Journal of Economics and Sociology Vol 67 No5, 2008: 915-940.

[10] Bierman, Dick J, Arnaud Destrebecqz, and Axel Cleeremans. "Intuitive decision making in complex situations: somatic markers in an artificial grammar learning task." Cognitive, affective and behavioural neuroscience, 2005: 297-305.

[11] Blustein, David L. "Decision-making styles and vocational maturity: An alternative perspective." Journal of Vocational Behavior Vol 30, 1987: 61-71.

[12] Bolger, Niall. "Coping as a personality process: A prospective study." Journal of Personality and Social Psychology Vol 59, 1990: 525-537.

[13] Bolger, Niall, and Elizabeth A Schilling. "Personality and the Problems of Everyday Life: The Role of Neuroticism In Exposure and Reactivity to Daily Stressors." Journal of Personality Vol 59 No 3, 1991: 355-386.

[14] Bosson, Jennifer K, Ryan P Brown, and Virgil Zeigler-Hill. "Self-Enhancement Tendencies Among People With High Explicit Self-Esteem: The Moderating Role of Implicit SelfEsteem." Self and Identity Vol 2, 2003: 169-187.

[15] Branden, Nathaniel. The psychology of self-esteem. A new concept of man's psychological nature. Los Angeles: Nash, 1969.

[16] Brown, Jonathan D, and Margaret A Marshall. "The Three Faces of Self-Esteem.” In M. Kernis (Ed.), Self-esteem: Issues and answers New York: Psychology Press, 2001: 4-9.

[17] Brown, Jonathon D, and Keith \& Dutton. "The thrill of victory, the complexity of defeat: self-esteem and people's emotional." Journal of Personality and Social Psychology Vol 68, 1995: 712-722.

[18] Burns, Robert B. The Self-concepts in Theory, Measurement, Development and Behaviour. London: Longman, 1979. Butler, Richard. Designing Organizations: A Decision Making Perspective. London: Routledge, 1992. 
[19] Campbell, Jennifer D. "Self-esteem and clarity of the selfconcept." Journal of Personality and, 1990: 538-49.

[20] Cattell, Raymond B. "The description of personality. Principles and findings in a factor analysis." American Journal of Psychology Vol 58, 1945: 69-90.

[21] Cervone, Frank H. "Making decisions: Methods for digital library project teams." OCLC Systems \& Services, Vol. 21 No 1, 2005: 30-35.
[22] Chartrand, Judy. M, Mellisa L Rose, Timmothy R Elliott, Cheri Marmarosh, and Susan Caldwell. "Peeling Back the Onion: Personality, Problem Solving, and Career DecisionMaking Style Correlates of Career Indecision.” Journal of Career Assessment Vol 1, 1993: 66-84.

[23] Costa, Paul T Jr, and Robert R McCrae. "Comparison ofEPI and Psychoticism scales with measures of the five factor model of personality." Personality and Individual Differences Vol 6, 1985: 587-597. 